\title{
A remição da pena pela literatura na Penitenciária de Maringá
}

\section{Selson Garutti ${ }^{1}$ e Taiz de Faria Lara ${ }^{2}$}

1 Doutor em Educação pela Universidade Estadual de Ponta Grossa Paraná. Professor de Filosofia da Secretaria de Educação do Paraná, Brasil.

E-mail: selsongarutti@hotmail.com 19 http://lattes.cnpq.br/9230755254023658 1 http://orcid.org/0000-0001-5348-7842

2 Doutoranda em Direito. Mestrado em Educação pela UEM, Bacharel em Direito ela CESUMAR; Licenciada em Português e Literaturas de Língua Portuguesa pela UEM e Licenciada em Pedagogia pela UNINTER, Brasil.

E-mail: fariaslara@yahoo.com.br 1 http://orcid.org/0000-0002-9359-1828

RESUMO: Com o objetivo de analisar o Projeto Remição da Pena pela Leitura (Lei no 17.329/12) aplicado na Penitenciária Estadual de Maringá-PR (PEM-PR), de modo a evidenciar relevâncias efetivas, bem como, lacunas a serem preenchidas. Pesquisa documental de caráter exploratória, usando como referencia teórico de Candido (1972; 1992; 2004). Como resultado, pode-se afirma que mesmo havendo um aumento real de $215 \%$ de resenhas produzidas entre 2012 e 2017, há de se ponderar que ainda existem alguns aspectos com necessidade de ampliação, tais como maior número de livros específicos para o Projeto de Remição pela Leitura, além de um maior número de professores envolvidos com essa finalidade.

Palavras-Chave: Leitura. Literatura. Remição.

\section{Redemption of the penalty literature on Penitentiary of the Maringá}

ABSTRACT: The aim of this study is to analyze the project Remission of the Sentence by Reading (Law $n$-. 17.329/12) applied to Maringá-PR State Penitentiary, in order to show effective relevance, as well as gaps to be filled. Documentary research exploratory character, using theoretical reference de Candido $(1972 ; 1992 ; 2004)$. As a result, it can be said that even though there is a real increase of $215 \%$ of reviews produced between 2012 and 2017, it should be considered that there are still some aspects that need to be expanded, such as more specific books to the Project remission, besides to a greater number of teachers involved in this project.

Keywords: Reading. Literature. Remission.

\section{INTRODUÇÃO}

A leitura faz parte do arcabouço cultural humano e desempenha a função de ensinar, divertir, refletir e etc., movimentos essenciais para a formação humana. Então a literatura é um direito tanto quanto todos os outros direitos aos que os Seres Humanos têm direito. Constituindo assim, o processo de humanização integral. Processo que:

[...] confirma no homem aqueles traços que reputamos essenciais, como o exercício da reflexão, a aquisição do saber, a boa disposição para com o próximo, o afinamento das emoções, a capacidade de penetrar nos problemas da vida, o senso da beleza, a percepção da complexidade do mundo e dos seres, o cultivo do humor. A literatura desenvolve em nós a quota de humanidade na medida em que nos torna mais compreensivos e abertos para a natureza, a sociedade, o semelhante. (CANDIDO, 2004, p. 180).

Cândido (2004, p.175) salienta que "(...) a literatura confirma e nega, propõem e de- 
nuncia, fornecendo a possibilidade de vivermos dialeticamente os problemas". A literatura provoca uma crítica a estereótipos cristalizados, constituindo um exercício reflexivo, uma:

[...] aventura que pode causar problemas psíquicos e morais, como acontece com a própria vida, da qual é imagem e transfiguração. Isto significa que ela tem papel formador de personalidade, mas não segundo as convenções; seria antes segundo a força indiscriminada e poderosa da própria realidade. Por isso, nas mãos do leitor o livro pode ser fator de perturbação e mesmo de risco (CANDIDO, 2004, p. 176).

Como consequência, constata-se ser literatura um fundamento educativo, que estimula a reflexão proporcionando instrumentais capazes de analisar a conjunturas na atualidade.

Além do desenvolvimento intelectual e cultural, produz axiomas indispensáveis para a humanização. Cândido (2004) ainda salienta que tanto os axiomas preconizados quando os axiomas refutados estão implícitos em variadas expressões, qual faz um gatilho disparador de conceitos que instrumentaliza a leitura em interpretação social entre leitor, realidade e obra.

Jouve (2002, p. 61) salienta que "[...] a leitura, de fato, longe de ser uma recepção passiva, apresenta-se como uma interação produtiva entre texto e leitor. A obra precisa, em sua constituição, da participação do destinatário". Porque "[...] toda leitura interage com a cultura e os esquemas dominantes de um meio e de uma época" (JOUVE, 2002, p.22).

Além dessa interação, ainda existem outros aspectos a serem considerados no e do texto literário. Entre tantos a serem salien- tado, um dos mais destacáveis, consiste no aspecto do imaginário, pois cada leitor desperta pela imaginação tanto sobre aspectos da criatividade quanto por aspectos constrangedores e difíceis na e da vida em sociedade.

Então o fazer literário:

[...] se baseiam numa espécie de necessidade universal de ficção e de fantasia, que de certo é coextensiva ao homem, pois aparece invariavelmente em sua vida, como indivíduo ou como grupo, ao lado da satisfação das necessidades mais elementares. $E$ isto ocorre no primitivo e no civilizado, na criança e no adulto, no instruído e no analfabeto. A literatura propriamente dita é uma das modalidades que funcionam como resposta a essa necessidade universal. (CANDIDO, 1972, p. 804).

Ficção que contenha elementos da realidade vivida, tanto pela cultura quanto pela arte, mecanismo ou de transformação, ou de sedimentação da realidade, propiciando condições ou de sonhos, ou de ilusões, ou de realidade. Lugar social de onde se cria e recria expectativas e vicissitudes. Logo, "[...] o ato de ler qualifica-se como uma prática indispensável para o posicionamento correto e consciente do indivíduo perante o real" (ZILBERMAN, 1991, p.17).

É nesse contexto que a prática social da leitura adquire caráter pedagógico, haja vista pertencer ao fazer pedagógico e às transformações sociais. Dai entender a literatura como "[...] prática social. Enquanto tal, não pode prescindir de situações vividas socialmente, no contexto da família, da escola, do trabalho, (...)" (SILVA, 1993, p.47). Obtém-se assim "[...] um modo particular de vivenciar o real: o texto torna-se o intermediário entre o sujeito e o mundo. (...) Por isso, ler passa a significar viver a reali- 
dade por intermédio do modelo do mundo transcrito no texto" (ZILBERMAN, 1991, p.18). Proposição o qual, coloca o ficcional literário em consonância com as necessidades humanas como complemento da imaginação.

Cândido (1972, p.804) salienta que "[...] a necessidade de ficção se manifesta a cada instante, aliás, ninguém pode passar um dia sem consumi-la, ainda que sob a forma de palpite na loteria, devaneio, construção ideal ou anedota". Vale a exortação de Cândido (1972) sobre tais fantasias, nunca se manifestam em sua forma pura, pois emergem de um contexto real, o qual anseia por compreensão, por estarem ligados aos costumes sociais de grupos humanos.

Logo, o fato imaginativo se concretiza no real. Então "[...] a obra literária significa um tipo de elaboração das sugestões da personalidade e do mundo que possui autonomia de significado; mas que esta autonomia não a desliga das suas fontes de inspiração no real" (CANDIDO, 1972, p. 806).

Nesse contexto, a literatura trabalha como imaginação, a qual denota a realidade literária. De que a imaginação está permeada pelo concreto e vice versa. Assim problematiza-se a realidade, posto que tais proposições questionem a verdade imputada como absoluta. Questionamentos que inquietam os sujeitos do e no mundo, o que leva a refletir e refazer-se.

Interação axiológica entre obra e leitor, persuadindo o leitor a refletir. Culminando em catarse, transformando pensamentos em questionamentos e, questionamentos em proposições:

O encontro entre o leitor e o texto literário se realiza a partir da catarse, que é o envolvimento emocional e intelectual pelo qual se concretiza a identificação do leitor com os traumas funcionais. As histórias lidas ou contadas contribuem para o encontro do ouvinte para as estratégias da narrativa e as convenções da língua escrita, atraindo o interesse do aluno para conhecer as mesmas histórias nos livros, possibilitando o contato com outros textos (AMARILHA, 2006, p.75).

Assim, para haver relação entre as partes, é condicionante envolver o leitor de forma emocionalmente, ler para obter prazer e, com isso ser gradativamente atraído para o universo literário. Na mesma proporção que deva ser um bom ouvinte para ouvir as posições contrarias do já lido. Contexto de contradições, o qual acaba por desperta a curiosidade epistemológica, o a qual o levará a pesquisar mais sobre o tema para conhecê-lo melhor (AMARILHA, 2006).

Em consonância, criações ficcionais interagem de modo subconsciente, operando:

[...] uma espécie de inculcamento que não percebemos. (...) as camadas mais profundas de nossa personalidade podem sofrer um bombardeio poderoso das obras que lemos e que atuam de maneira que não podemos avaliar. Talvez os contos populares, as historietas ilustradas, os romances policiais ou de capa-e-espada, as fitas de cinema, atuem tanto quanto a escola e a família na formação de uma criança e de um adolescente. (CANDIDO, 1972, p. 805).

De fato, literatura é tanto formativa quanto informativa, podendo ser até deformativa, a qual difere do conceito educacional tradicional já constituído, o qual se efetua por que:

A literatura pode formar; mas não segundo a pedagogia oficial, que costuma vê-la ideologicamente como um veículo da tríade famosa, o Verdadeiro, o Bom, o Belo, definidos con- 
forme os interesses dos grupos dominantes, para reforço da sua concepção de vida. Longe de ser um apêndice da instrução moral e cívica (...), ela age com o impacto da própria vida e educa como ela, - com altos e baixos, luzes e sombras. (CANDIDO, 1972, p. 805).

Assim, a literatura recorta o real, interpreta e sintetiza a realidade pelo viés do leitor, construindo digressões entre ficção versus realidade, o que produz um saber interpretativo do real. Veículo patrimonial de nossos conceitos, provocados por contradições em relação aos saberes outorgados, gerando neoreflexões com desdobramentos de atitudes possíveis.

Condições permeadas por variadas expectativa, não só dadas pela escola, mas também, expressas pelas bibliotecas, livrarias, sebos, cinemas e alternativas constituídas pela leitura que viabiliza e valorizam o acesso a esse bem cultural de valor inestimável, pois a leitura "[...] estimula sempre o diálogo, as trocas de experiências de vida, os gostos e desgostos" (OLIVEIRA 2010, p. 42). A literatura está para além dos limites escolares, pois com suas proposições tornase instrumento de entendimento sociocultural do mundo.

Sobre essa questão Suassuna (1995, p.52) afirma que:

Se o aluno lê sem prazer, sem o exercício da crítica, sem imaginação; se ele lê e não faz disso uma descoberta ou um ato de conhecimento; se ele só reproduz, nos exercícios, a palavra lida do outro, não há nisso nada que Ihe possibilite uma intervenção sobre aquilo que historicamente está posto.

Assim, a literatura produz conhecimento, tanto a acadêmica quanto a por prazer, contribui com a formação na totalidade. Certo de que a literatura não se imputa co- mo texto acabado que obriga o leitor a aceitar passivamente suas proposições. Ao contrário, define-se como "[...] um processo contínuo de descoberta e de autocriação" (OLIVEIRA, 2010, p. 42).

Proposição que vislumbra ainda mais, a literatura possuidora de uma força humanizadora, por contribuir com a formação humana nos moldes pedagógicos em sentido criativo. Associa a literatura à experiência de cunho formal, informal e não formal, promove conhecimento, ensinamento, criatividade e todas mais relações possíveis daí advindas.

Então Candido (2004, p. 186) relaciona os direitos humanos com a literatura:

Primeiro verifiquei que a literatura corresponde a uma necessidade universal que deve ser satisfeita sob pena de mutilar a personalidade, porque pelo fato de dar forma aos sentimentos e à visão do mundo, ela nos organiza, nos liberta do caos e, portanto, nos humaniza. Negar a fruição da literatura é mutilar a nossa humanidade. Em segundo, a literatura pode ser um instrumento consciente de desmascaramento, pelo fato de focalizar as situações de restrição dos direitos, ou de negação deles, como a miséria, a servidão, a mutilação espiritual. Tanto num nível quanto no outro ela tem muito a ver com a luta pelos direitos humanos.

Ainda sobre humanização, Candido (1992, p.13) escreveu em seu ensaio:

Na sua despretensão, humaniza; e esta humanização Ihe permite, como compensação sorrateira, recuperar com a outra mão uma certa profundidade de significado e um acabamento de forma, que de repente podem fazer dela uma inesperada embora discreta candidata à perfeição.

Nessa contingência, a leitura acaba por 
ampliar os horizontes, tanto de forma exógena quanto endógena, constituindo relações polissêmicas provocando no leitor:

[...] reações diversas que vão do prazer emocional ao intelectual. Além de simplesmente fornecer informação sobre diferentes temas, histórias sociais, existenciais e éticas [...], eles também oferecem outro tipo de satisfação ao leitor; adquirir conhecimentos variados, viver situações existenciais, entrar em contato com novas ideias (FARIA, 2004, p. 12).

Também Oliveira e Spindola (2008) convergem sobre a viagem que um texto de qualidade pode proporcionar ao seu leitor, contemplando diversos processos. Então leitura exerce funções correlatas de formação cultural, intelectual, social e etc., compreensão, a qual é proporcionada pela cosmovisão de seu arcabouço literário.

A leitura relaciona imaginação, criação e realidade dada pela influência entre o possível e o impossível, postulado pela criatividade. Então a leitura estabelece conhecimentos capazes de compreensão das relações permeadas no mundo (COLOMER, 2003).

Em síntese, compreende-se a leitura como:

[...] uma atividade ao mesmo tempo individual e social. É individual porque nela se manifestam particularidades do leitor: suas características intelectuais, sua memória, sua história; é social porque está sujeita às convenções linguísticas, ao contexto social, à política. (NUNES, 1994, p. 14).

Ler tornou-se atividade significativa, interação entre texto e contexto, produzindo pretexto / intencionalidade. Tripé o qual, converge para que $\mathrm{o}$ ato de ler se torne uma prática social, enquanto fonte de in- formação, formação e difusão da cultura literária. Assim, fica explicitado, ser a leitura uma prática social inclusiva, haja Vista que ler:

[...] significa ser questionado pelo mundo e por si mesmo, significa que certas respostas podem ser encontradas na escrita, significa poder ter acesso a essa escrita, significa construir uma resposta que integra parte das novas informações ao que já se é, (FOUCAMBERT, 1994, p.05).

Se ler se constitui como prática social, então é preciso ir além do saber ler, pois é fundamental saber utilizar o que se lê e o que se escreve como meio de interação na sociedade.

Ler se faz por interações multidisciplinares, dadas por axiomas estabelecidos pelos grupos sociais com interesses definidos em uma sociedade de classes. Assim, ler contribui para formar Cidadão. Portanto, ler contribui para a formação cidadã, pela qual, constitui novas relações "[...] de forma dinâmica, crítica e autônoma, tornando-se sujeito construtor de sua própria história e da história coletiva de seu país" (ROSA, 2005, p.05).

Para Takahashi $(2000,2000$, p.45):

Formar o cidadão não significa 'preparar o consumidor'. Significa capacitar as pessoas para a tomada de decisões e para a escolha informada acerca de todos os aspectos na vida em sociedade que as afetam, o que exige acesso à informação e ao conhecimento e capacidade de processá-los judiciosamente, sem se deixar levar cegamente pelo poder econômico ou político.

A leitura deve ser essencial na educação e, assim, tornar-se a base da sociedade, a qual prioriza as relações pedagógicas dadas 
entre conhecimentos e aprendizagem. Dai reconhecer o valor da leitura como prioridade na vida dos sujeitos, tem-se por intenção formar leitores capazes de participar na e pela sociedade de forma autônoma como a um cidadão.

\section{REMIÇÃO PELA LEITURA}

A lei no 17.329 de 08/10/2012 respalda a remição pela leitura, publicada no Diário Oficial $n=8.814$ de 08/10/2012. A qual institui o Projeto "Remição pela Leitura", nos Estabelecimentos Penais do Paraná e é composta de vinte e cinco artigos. O Programa de remição pela leitura iniciou em maio de 2012, transformado em lei em outubro. Em Maringá, atende o complexo prisional: Penitenciária, Colônia Penal Industrial e Casa de Custódia.

Conforme a Lei no 12.433, de 29/06/ 2011, o Programa de remição pela leitura é um meio de viabilizar a remição da pena através de estudo. Objetiva-se oportunizar ao apenado remir parte de sua pena pela leitura mensal, pode ser literatura, filosofia, científico ou didático, oportunizando o conhecimento, educação, cultura e capacidade crítica. Após a leitura, acontece a segunda fase que é a elaboração de relatório de leitura ou resenha.

A Lei também destaca que poderão participar do projeto aqueles que ainda não têm acesso à escolarização. Os responsáveis pela implantação e acompanhamento do projeto é o Programa de Desenvolvimento Integrado (PDI) e o Departamento Penitenciário (DEPEN), intermediado pela Secretaria de Estado da Justiça, Cidadania e Direitos Humanos (SEJU) e implementados e orientados pela Divisão Ocupacional e de Qualificação (DIOQ).
Quanto à participação do preso, esta será voluntária e cumulativa se houver outra atividade de remição paralela, cabendo ao setor de Pedagogia fazer a inscrição do aluno.

Aos presos alfabetizados do Ensino Fundamental - Fase I e II, destina-se o trabalho de relatório de leitura e para os alfabetizados de Ensino Médio, Pós Médio, Superior e Pós Superior, a resenha, resumo e apreciação crítica. Após a leitura da obra e elaboração de cada resenha, os presos recebem remição de quatro dias em sua pena. Entretanto, o leitor só poderá escolher uma obra e fazer a resenha num período de trinta dias.

Quanto à elaboração do trabalho, este deve ser feito individualmente, presencial e em local adequado perante o professor de Língua Portuguesa destinado à tarefa de acompanhar o Programa. Após a elaboração da versão final do trabalho, será mensurada por uma nota que pode ser de zero a dez e é aprovado o texto com nota igual ou superior a seis, segundo o sistema de avaliação adotado pela Secretaria de Estado da Educação do Paraná - SEED / PR.

Para a organização e um bom andamento do projeto, deve-se elaborar um cronograma mensal para a triagem dos livros, assim como, a elaboração do texto. Tais livros devem compor o acervo bibliográfico indicado pela comissão de Remição pela Leitura.

No que diz respeito aos envolvidos nessa Comissão, em cada Estabelecimento Penal, deve ser composta por um professor de Língua Portuguesa do CEEBJA de cada unidade penal, um pedagogo responsável pelo acompanhamento do Programa ou o pedagogo do CEEBJA em que está inserido o Programa. Convém destacar que em con- 
formidade ao artigo no 130 da Lei no 7.210, de 11/07/1984, os integrantes da Comissão de Remição pela Leitura que atestarem com falsidade um pedido de remição será constituído crime.

É de responsabilidade da Comissão da Remição pela Leitura, que os envolvidos devam relacionar as obras que compõem ações da Remição da pena através da Leitura, atualizar periodicamente o acervo, orientar os apenados sobre redigir textos, corrigir e orientar como reescrever, corrigir a versão final do textual e declarar mensalmente o comprovante das leituras realizadas, contendo carga horária e aproveitamento escolar advindos da remição.

Destaca-se que toda equipe de execução penal deverá ser responsável pela execução do Programa. O Estado poderá firmar convênios para a execução do Projeto. Cabe aos órgãos responsáveis promover exposições, rodadas de leitura, concursos literários e outras atividades culturais que envolvam os participantes do Programa. Já o atestado de remição será emitido pelo CEEBJA de cada unidade. Além de responsáveis pelo seu arquivamento. $O$ atestado deve ser disponibilizado mensalmente e a remição ser declarada pelo juiz para a execução da pena.

\section{OBJETIVOS}

Com o objetivo de analisar o Projeto Remição da Pena pela Leitura aplicada na PEM-PR, o qual oportuniza aos Sujeitos Apenados remirem parte de sua pena pela leitura mensal, de modo a evidenciar relevâncias efetivas, bem como, lacunas a serem preenchidas.

\section{MATERIAIS E MÉTODOS}

A elaboração dos objetivos desta proposta parte da análise do material documental, existente nos arquivos do Setor Pedagógico, apenso ao setor da Divisão Ocupacional de Qualificação da PEM-PR (DIOQ-PEM-PR), constituídos pelo Projeto de Remição pela Leitura ofertada aos apenados entre 2012 e 2017. Além das fontes documentais, levouse em consideração as bibliográficas e jurídicas produzida sobre remição.

Faz-se necessário explicitar as normas do projeto Remição da Pena por Estudo, através da leitura: Ensino Fundamental - Fase I: Livros com muita ação e diálogo, com narração sequencial, temas agradáveis e de fácil assimilação, mas que oportunizam reflexão. Ensino Fundamental - Fase II: Especificamente livros da literatura brasileira, como contos, ficção, aventuras e romances. Ensino Médio e Superior: Clássicos da literatura brasileira e universal, elencados como ficção, autobiografias, história, sociologia, política, filosofia e romances.

Seguidos pelos critérios de correção:

\begin{tabular}{|c|c|c|c|}
\hline \multirow[t]{2}{*}{$\begin{array}{c}\text { Critérios de } \\
\text { avaliação }\end{array}$} & $\begin{array}{c}\text { Domínio da } \\
\text { norma padrão }\end{array}$ & Estética & \begin{tabular}{|c|} 
Estrutura lógica \\
e qualidade de \\
texto
\end{tabular} \\
\hline & $\begin{array}{l}\text { Ortografia acen } \\
\text {-tuação gráfica } \\
\text { concordância } \\
\text { nominal/ver- } \\
\text { bal/regência } \\
\text { nominal/verbal } \\
\text { /pontuação. }\end{array}$ & $\begin{array}{l}\text { Cumpre o nú } \\
\text {-mero míni- } \\
\text { mo (30) e } \\
\text { máximo (60) } \\
\text { de linhas es- } \\
\text { pecificadas. } \\
\text { Legibilidade } \\
\text { da letra, pa- } \\
\text { ragrafação e } \\
\text { disposição } \\
\text { do texto. }\end{array}$ & \begin{tabular}{|l} 
Paragrafação e \\
disposições es- \\
peciais do texto. \\
O resumo/rese- \\
nha é condizente \\
com a obra lida? \\
Há considera- \\
ções do apenado \\
sobre a mensa- \\
gem da obra? \\
Limitação ao con \\
-teúdo do livro e \\
coerência?
\end{tabular} \\
\hline Valor: & 40 & 20 & 40 \\
\hline Nota: & & & \\
\hline
\end{tabular}

Fonte: Cabeçalho da folha da versão definitiva. 
Na resenha deva conter: Uma síntese, com a apresentação das principais ideias do autor; Uma análise aprofundada de pelo menos um ponto relevante do livro; Uma apreciação do texto. Por fim, uma conclusão dada segundo o leitor fechando o texto (PARANÁ, 2012).

\section{LÓCUS DA PESQUISA}

A PEM-PR caracteriza-se como estabelecimento de segurança máxima. Com capacidade para 360 presos, dos quais, um percentual razoável está fixado nos canteiros de trabalho nas diversas áreas. Também, um percentual estuda no CEEBJA Professora Tomires Moreira de Carvalho, alocado no seu interior, pelo qual, é oferecido escolarização.

\section{RESULTADOS E DISCUSSÃO}

Após a pesquisa no DIOQ-PEM-PR, observaram-se, inicialmente, os números de produções de textos concluídos, ou seja, os dados a seguir se referem àqueles que concluíram a terceira versão do texto para conseguir a remição. Também é preciso esclarecer que os três primeiros anos (2012; 2013; 2014) a nomenclatura utilizada era ciclo \& ano, só nos anos seguintes (2015; 2016; 2017;) passou a ser classificado por meses \& ano, conforme segue:
Gráfico 01: Ciclo de 2012

Chart 01: Cycle of 2012

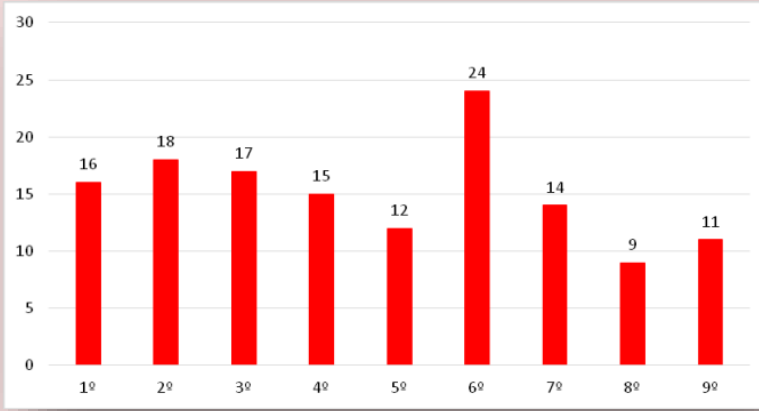

Fonte: DIOQ-PEM.

O ano de 2012 marca o início do Projeto da Remição pela Leitura, mesmo tendo começado no meio do ano, houve uma relevante procura por parte dos apenados.

\section{Gráfico 02: Ciclo de 2013}

Chart 02: Cycle of 2013

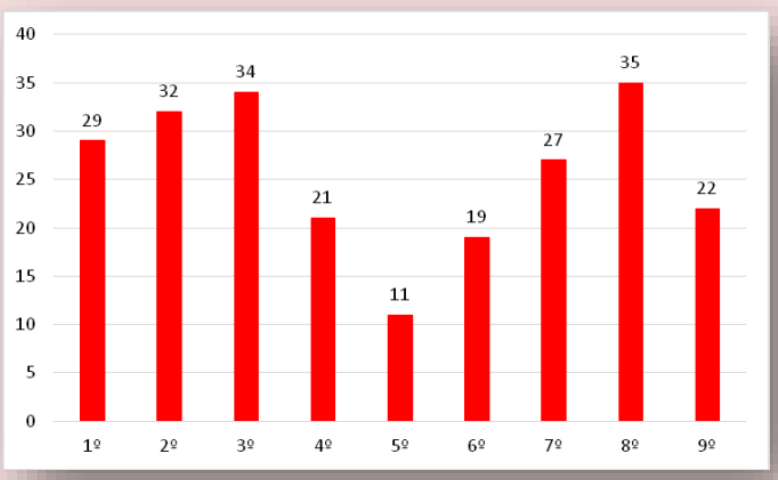

Fonte: DIOQ-PEM.

Em 2013, houve uma oscilação em torno de vinte livros lidos mensalmente. É destacável que ainda nesse início não havia professor para atender ao Programa. Entretanto, os outros professores colaboravam. Contava-se também com os estagiários que contribuíram na correção. Mesmo assim, de 2012 para 2013 houve um aumento de 60\% de resenhas. 


\section{Gráfico 03: Ciclo de 2014 \\ Chart 03: Cycle of 2014}

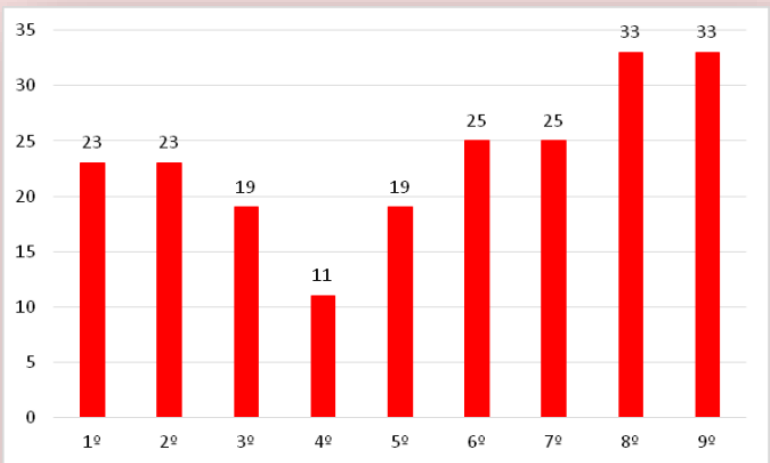

Fonte: DIOQ-PEM.
Gráfico 04: Ano de 2015

Chart 04: Year of 2015

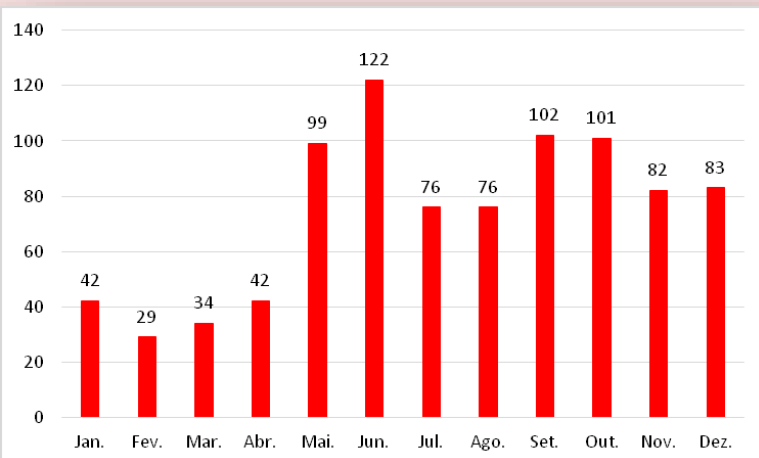

Fonte: DIOQ-PEM
No ano de 2014, o Sistema Carcerário do Paraná passou por uma crise na segurança, o que repercutiu na totalidade do Sistema. Em consequência, não houve avanços no número de resenhas, ao contrário, de 2013 para 2014 houve um decréscimo de $8 \%$ resenhas.

Mas de 2014 para 2015 houve uma mudança significativa, por causa do concurso público para três Professores (um para cada Unidade) em conjunto entre as Secretarias da Educação e da Justiça, para Professores de Língua Portuguesa para atuarem especificamente no Projeto da Remição da Pena pela Leitura. Os quais foram contratados em Julho de 2014.
Os efeitos da contratação só surtiu efeito em 2015 devido à formação específica tanto para o Sistema Prisional quanto para o Projeto de Remição. Logo, o aumento significativo do Programa só ocorreu pelo empenho dos professores no acompanhamento das resenhas corrigidas. Assim, de 2014 para 2015 houve um aumento significativa de $76 \%$ de resenhas.

Deve-se levar em conta a crescente procura para fazer parte dessa viabilidade remissória. Destacando que haja apenas uma busca pela remição da pena, o participante ao entrar no Projeto, acaba passando por um processo formativo, isso em consequência de que tanto a literatura, quanto a arte, são proposições pedagógicas formativas. 
Gráfico 05: Ano de 2016

Chart 05: Year of 2016

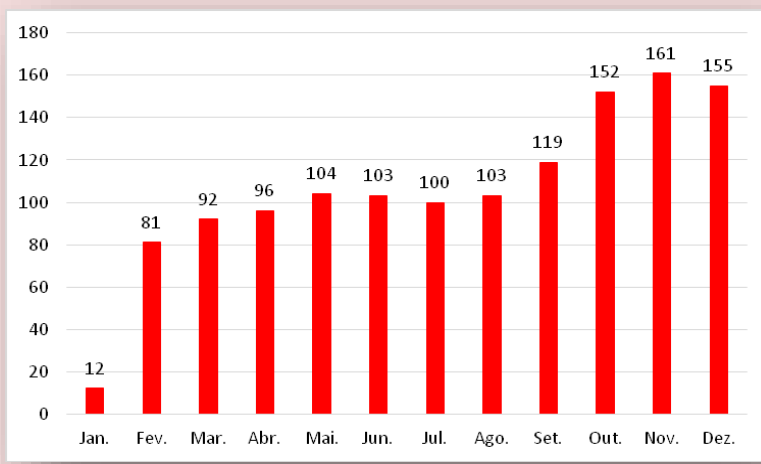

Fonte: DIOQ-PEM.

Ao analisar o ano de 2016, percebe-se um relativo aumento na produção das resenhas, sendo que, de 2015 para 2016 houve um aumento de $31 \%$ de resenhas produzidas.

Gráfico 06: Ano de 2017

Chart 06: Year of 2017

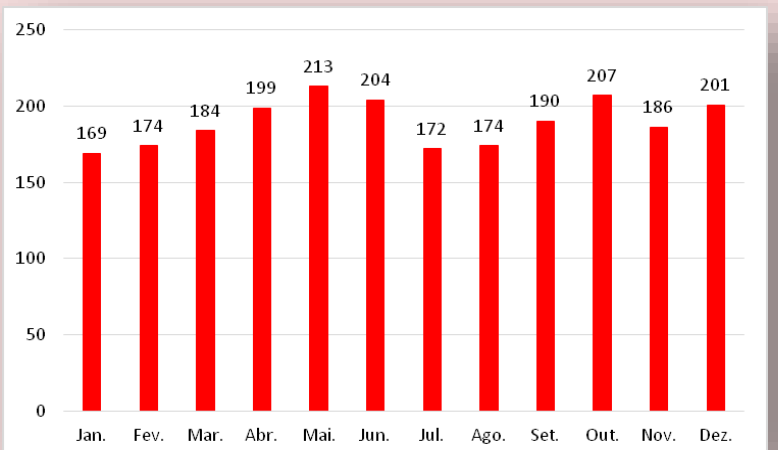

Fonte: DIOQ-PEM.

Ao analisar os dados obtidos pela pesquisa, destacam-se os cinco anos de atividade em vigor na PEM. Após levantamento do número de livros lidos e os textos produzidos, confere-se que houve um crescimento significativo no decorrer dos anos vigentes. Tanto que de 2016 para 2017 houve mais um aumento de $56 \%$ de resenhas produzidas.
Gráfico 07: Total de livros lidos nos anos de 2012 a 2017

Chart 07: Total of books read from 2012 to 2017

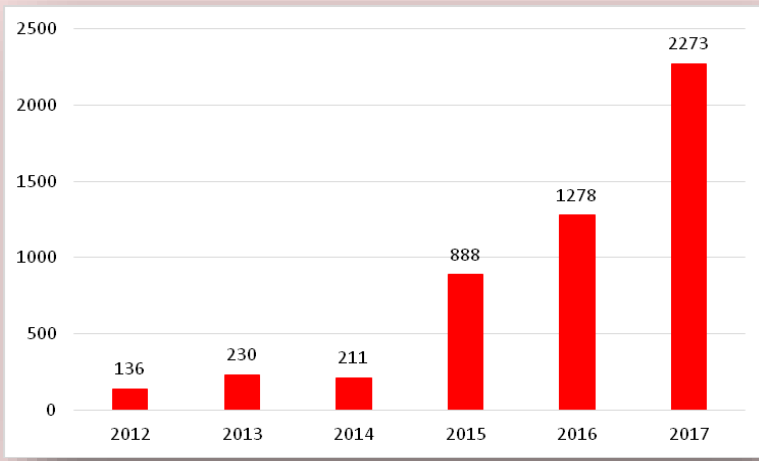

Fonte: DIOQ-PEM.

Tendo 2017 por referência do último ano, houve um aumento de $223 \%$, descartando o decréscimo de $8 \%$ de 2014 , totalizou-se um aumento real de $215 \%$ de resenhas. Um aumento significativo na busca pelo Projeto de Remição pela Leitura na PEM-PR.

\section{CONSIDERAÇÕES FINAIS}

Após a teorização sobre leitura, assim como sobre os dados do Projeto Remição pela Leitura, além da contextualização de como funciona tais atividades, em deferência de que há uma aceitação e busca pela participação em níveis crescentes, sobretudo em consequência de 2015 . Há um relevante número de participantes com seus textos elaborados.

Entretanto, o Sistema Prisional carece tanto de um maior número de livros específicos a esta atividade, quanto de professores imprescindíveis para atenderem o Projeto de Remição por Leitura. Espera-se que essa ação pedagógica, transformada em lei, seja efetivamente ampliada e que assim, através da leitura, inclua-se um currículo abrangente e, que não estabeleça somente 
remição de penas, mas contribua para a construção intelectual dos apenados em busca da liberdade pelos sentidos possíveis, sendo a leitura uma das portas possíveis de saída do cárcere e que cada residente dessa Unidade a encontre efetivamente.

Por fim, o Programa se apresenta com resultados satisfatórios e permitem a formação dos apenados naquilo que concerne aos atributos advindos da leitura. Entretanto, é preciso ampliar a oferta em se tratando do número de leitores, pois após a chegada da professora para este fim, somente ela atendeu a sua unidade, considerando necessário corrigi-los por três vezes, arquivá-los e cadastrar no sistema cada sujeito com sua produção textual.

\section{REFERÊNCIAS}

AMARILHA, M. Alice que não foi ao país das maravilhas: leitura crítica na sala de aula. Petrópolis, RJ: Vozes, 2006.

BRASIL. Ministério da Justiça. Lei no 12.433, de 29 de junho de 2011. Altera a Lei no. 7.210, de 11 de julho de 1984 (Lei de Execução Penal), para dispor sobre a remição de parte do tempo de execução da pena por estudo ou por trabalho.

BRASIL. Ministério da Justiça. Lei no. 7.210, de 11 de julho de 1984. Institui a Lei de Execução Penal.

CANDIDO, A. A crônica: o gênero, sua fixação e suas transformações no Brasil. Campinas, SP: Unicamp; Rio de Janeiro: Fundação Casa de Rui Barbosa, 1992, p.13-14.

CANDIDO, A. A literatura e a formação do homem. In: Ciência e Cultura, XXIV Reunião da SBPC. São Paulo, SP, vol. 24, n. 09, set. 1972, p.803-809.

CANDIDO, A. O direito à literatura. In: Vários Escritos. 4. ed. Duas cidades: Ouro so- bre azul. São Paulo; Rio de Janeiro. 2004, p.169-191.

COLOMER, T. A formação do Leitor Literário. São Paulo: Global, 2003.

FARIA, M. A. Como usar a literatura infantil na sala de aula. São Paulo: Contexto, 2004. FOUCAMBERT, J. A leitura em questão. Porto Alegre: Artes Médicas, 1994.

JOUVE, V. A leitura. Tradução Brigitte Hervot. São Paulo: UNESP, 2002.

NUNES, J. H. Formação do leitor brasileiro: Imaginário da leitura no Brasil colonial. São Paulo: UNICAMP, 1994.

OLIVEIRA, A. A. O professor como mediador das leituras literárias. In: Literatura. Brasília: Ministério da educação, 2010.

OLIVEIRA, A.; SPÍNDOLA, A. Linguagens na educação infantil II - literatura infantil. NEAD. CUIABÁ: EDUFMT, 2008.

PARANÁ. Secretária de Justiça. Lei no $\mathbf{1 7 . 3 2 9}$ de 08 de Outubro de 2012.

ROSA, E. Relatos autobiográficos de leitura e alfabetização: ouvindo professores para entender como pensam sobre o que ensinam. In: LEAL, Telma F.; ALBUQUERQUE, Eliana (Org.). Desafios da educação de jovens e adultos: construindo práticas de alfabetização. Belo Horizonte: Autêntica, 2005.

SILVA, E. Elementos de pedagogia da leitura. São Paulo: Martins Fontes, 1993.

SUASSUNA, L. Ensino de língua Portuguesa: uma abordagem pragmática. Campinas: Papirus, 1995.

TAKAHASHI, Tadao. (Org.). Sociedade da informação no Brasil: livro verde. Brasília: Ministério da Ciência e Tecnologia, 2000. ZILBERMAN, R. A formação do leitor. In: . A leitura e o ensino da literatura. 2. ed. São Paulo: Contexto, 1991, p. 15-20. 
(c)

(i)

EY License information: This is an openaccess article distributed under the terms of the Creative Commons Attribution License, which permits unrestricted use, distribution, and reproduction in any medium, provided the original work is properly cited.

Artigo recebido em 24 de outubro de 2018.

Avaliado em 25 de outubro de 2018.

Aceito em 07 de fevereiro de 2019.

Publicado em 28 de fevereiro de 2019.

\section{Como citar este artigo (ABNT):}

GARUTTI, Selson; LARA, Taiz de Faria. A remição da pena pela literatura na Penitenciária de Maringá. Estação Científica (UNIFAP), Macapá, v. 8, n. 2, p. 3-4, maio/ago. 2018. 